\title{
NASA Space Flight Human System Standards
}

Barry Tillman, Lynn Pickett, Lockheed Martin

Dane Russo, Ken Stroud, Jan Connolly, and Tico Foley, NASA Johnson Space Center

NASA has begun a new approach to human factors design standards. For years NASA-STD-3000, Manned Systems Integration Standards, has been a source of human factors design guidance for space systems. In order to better meet the needs of the system developers, NASA is revising its human factors standards system. NASA-STD-3000 will be replaced by two documents: set of broad human systems specifications (including both human factors and medical topics) and a human factors design handbook

\section{HUMAN FACTORS ENGINEERING STANDARDS AT NASA - PRESENT SYSTEM}

For the past 20 years NASA has had a single agency-wide human factors standard, NASA-STD3000, the Manned Systems Integration Standards. Although NASA-STD-3000 was intended to apply to all human space flight systems, the standard was written primarily to address the needs of the International Space Station (the emerging program at the time).

It became clear that NASA-STD-3000 was not completely fulfilling its goal. Portions were too general to meet the specific needs of the International Space Station. The Space Station program therefore tailored their own programspecific version of NASA-STD-3000. On the other hand, NASA-STD-3000 was too space-stationspecific to be the human factors standard for the new Crew Exploration Vehicle (CEV, a vehicle to replace the shuttle and eventually carry humans back to the moon and beyond). Therefore, a CEV program-specific human factors requirements document was prepared.

Also, because NASA-STD-3000 is an agencywide standard, reviews and procedures required for update make it expensive and time-consuming to revise. In 1995 the standard went through its first and only update since its publication in 1987. It has not kept current with technological changes or lessons learned.

NASA-STD-3000 was the "official" standard, but it was aging and was not applicable to any specific program. The source and implementation of human factors standards at NASA had become unclear.

Finally, the relative roles of human factors and space flight medicine was confusing. Both deal with the health, performance, and well-being of the human. NASA-STD-3000 includes medical topics such as requirements for nutrition and medical care. Yet other specific medical requirements exist in individual program specifications as well as in other NASA standards and policy documents.

\section{NEW SYSTEM WITH STANDARDS AND HANDBOOK}

To address the problems described above, NASA is creating new standards and a reference handbook.

NASA has recently completed standards for human space flight systems. The document is called NASA Space Flight Human System Standards (SFHSS). It consists of two-volumes:

Volume 1- Crew Health

This volume covers standards needed to support astronaut health (medical care, nutrition, sleep, exercise, etc.)

Volume 2 - Habitability and Environmental Health

This volume covers the standards for system design that will maintain astronaut performance (environmental factors, design of facilities, layout of workstations, and lighting requirements, for example). It includes classic human factors requirements.

The new standards document is written in general terms so that it is applicable to a broad range of present and future NASA systems. For example, the document does not specify a that a design should accommodate specific percentiles of a defined population. Rather, Volume 2 states that 
all programs shall define the user population and their size ranges. The design shall then accommodate the full size range of those users.

The Space Flight Human System Standards establish human-system standards in broad, general terms. The document then states that all new programs prepare system-specific requirements that will meet the general standards. This addresses what is actually happening at NASA; programs do write human factors requirements specific to their systems. What has been added is that the new standard sets the goals and guidelines that programspecific requirements must meet. The SFHSS establishes a set of baseline standards that will help insure humans are healthy, safe, and effective.

The detail design information in NASA-STD3000 will be updated as appropriate and included in a design handbook. The new document, the Human Integration Design Handbook (HIDH), will serve two major purposes:

1. A design guidance document to help insure designers create a system which safely and effectively accommodates the capabilities and limitations of space flight crews.

2. A guideline for writing the human factors requirements for specific systems. These requirements will ensure the system meets the standards in the Space Flight Human System Standards.

The handbook will be divided into topic areas which address the range of human operations in space:

- Anthropometry and Biomechanics

- Human Performance Capabilities

- Natural and Induced Environments

- Architecture and Facilities

- User Interfaces

- Hardware and Equipment

- Facility Management

- Extra Vehicular Activities (EVA)

Each of the above chapters and sub-chapters will be subdivided into modules with more detailed information. All the modules have a common format. The module elements are:

- Introduction

- Design Considerations

- Essential Considerations / Example Requirements
- Lessons Learned

- Example Solutions

- Background Research

- Research Needs

- References

- Applicable Standards

One advantage of the handbook format, is a shortened review cycle for non-critical information. This will permit more frequent update and expansion. The handbook will be on-line and is intended to be an up-to-date resource of information on humans in space.

\section{STATUS OF STANDARDS AND HANDBOOK}

The Space Flight Human System Standards are complete and part of the NASA system. The first issue of the Human Integration Design Handbook will be published at the end of 2007. Initially, the handbook will contain much of the information from NASA-STD-3000. After the first publication, work will continue to update, replace, and expand the handbook contents. 


\title{
NASA Space Flight Human System Standards
}

\author{
Dane Russo, Tico Foley, Ken Stroud, Janis Connolly \\ NASA Johnson Space Center \\ Houston, Texas \\ Barry Tillman, Lynn Pickett \\ Lockheed Martin \\ Houston, Texas
}

\begin{abstract}
NASA has begun a new approach to human factors design standards. For years NASASTD-3000, Manned Systems Integration Standards, has been a source of human factors design guidance for space systems. In order to better meet the needs of the system developers, NASA is revising its human factors standards system. NASA-STD-3000 will be replaced by two documents: set of broad human systems specifications (including both human factors and medical topics) and a human factors design handbook.
\end{abstract}

\section{INTRODUCTION}

Human factors engineering (HFE) at NASA is unique in many respects. Space flight crews are subjected to extreme environments including highacceleration launch and landing, zero gravity orbit, partial-gravity on lunar and planetary surfaces, and extended habitation with only remote support from mission control. To help deal with these challenges, HFE at NASA is integrating classic HFE design principles with the lessons learned from more than 40 years of human spaceflight in a new standard, NASA STD-3001 and a Human Integration Design Handbook.

Since 1987 human factors design guidelines and standards have been baselined in NASA's Manned Systems Integration Standards (MSIS), NASA-STD3000. Problems in implementing NASA-STD-3000 include the fact that it does not adequately address all space systems, it is not current with the latest human factors information, and many requirement statements in NASA-STD-3000 are not verifiable. NASA is currently making major revisions to these human factors design requirements and guidelines. The resulting new documents attempt to address some of the difficulties with the content and application of NASA-STD-3000 and update the data to reflect current research and agency organization. This paper will describe some of these difficulties and the approach NASA is taking in developing NASA STD-3001 and an accompanying design handbook, the Human Integration Design Handbook (HIDH).

\section{NASA-STD-3000 DESCRIPTION AND HISTORY}

In the mid-1980's NASA started the process of creating a NASA-wide set of HFE standards for all NASA space systems. The effort consolidated years of research of humans in space and earlier human factors design standards developed at Johnson Space Center and Marshall Space Flight Center.

The resulting standard was to address nearly all aspects of humans in space: habitability, environments, health, and human factors design requirements. The chapters in the standard included anthropometry, human performance, environment, safety, health, architecture, crew station design, hardware design, maintainability, facility management, and space-suited activities.

Experts from industry, NASA, and academia compiled the document. It underwent four major reviews and revisions by knowledgeable, potential users selected from government and industry. After a little more than one year the Manned Systems Integration Standards (MSIS), NASA-STD-3000, was completed in early 1987. The standard is still accessible today on NASA's website (http://msis.jsc.nasa.gov/).

\section{PROBLEMS WITH NASA-STD-3000}

While contributing significantly to the application of human factors to space systems, NASA-STD-3000 has not completely fulfilled its goals as stated in NASASTD-3000, Volume 1, Section 1:

- MSIS was expected to be "a single, comprehensive document defining all generic 
requirements for space facilities and related equipment." The International Space Station and the latest NASA program (the Constellation Program) have developed entirely new sets of requirements.

- MSIS was to be "kept current through an annual review process." The document has undergone only one major revision.

- The DESIGN REQUIREMENTS subsection was to "provide firm, contractually binding standards, requirements, and criteria. . ." Many of the requirements have been found too vague to make contractual compliance feasible and verifiable.

Many requirement statements were written too broadly to be applied at a program level. The intent was to cover all space systems, but this tended to generate requirements that were unverifiable on specific systems. The International Space Station (ISS) was the first application of NASA-STD-3000; however "unverifiable" standards resulted in a heavily edited version of NASA-STD-3000 for the human factors requirements for the ISS, which became SSP 50005.

On the other hand, NASA-STD-3000 was too spacestation-specific to be the human factors standard for the new Constellation Program Crew Exploration Vehicle (CEV, a vehicle to replace the shuttle and eventually carry humans back to the moon and beyond). Therefore, a CEV-specific human factors requirements document was prepared, resulting in NASA-STD-3000 Volume VIII for the CEV.

Because NASA-STD-3000 is an agency-wide standard, reviews and procedures required for update make it expensive and time-consuming to revise. In 1995 the standard went through its first and only update since its publication in 1987. It has not kept current with technological changes or lessons learned.

NASA-STD-3000 was the "official" standard, but it was aging and was not applicable to any specific program. The source and implementation of human factors standards at NASA had become unclear.

Another problem was that the relative roles of human factors and space flight medicine were confusing. Both deal with the health, performance, and well-being of the human. NASA-STD-3000 includes medical topics such as requirements for nutrition and medical care. Yet other specific medical requirements exist in individual program specifications as well as in other NASA standards and policy documents.

\section{NEW NASA HUMAN FACTORS STANDARD}

To address the problems described above, NASA has expanded and updated NASA-STD-3000 to create new standards and a reference handbook. The new documents are shown in Figure 1.

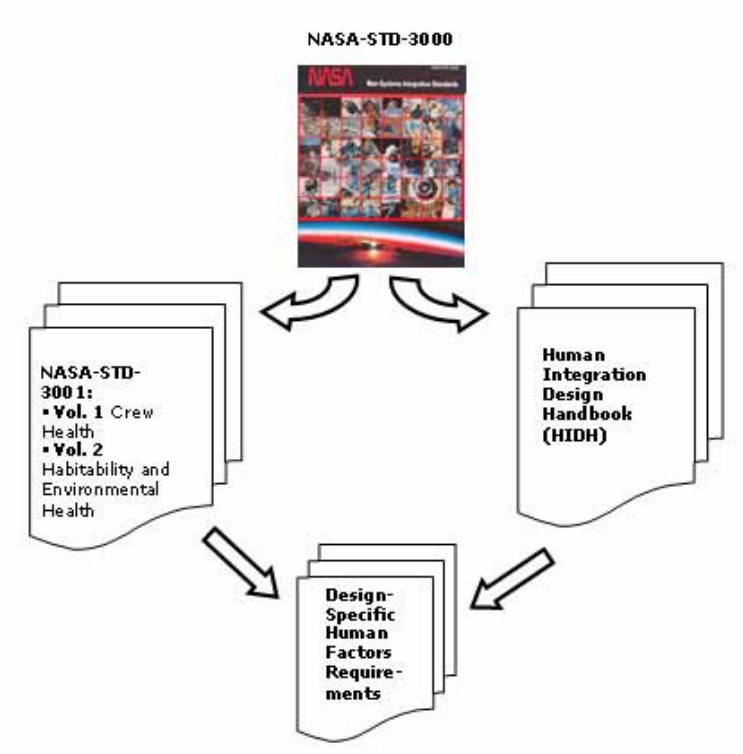

Figure 1. Changes in NASA Human Factors Standards and Requirements

NASA recently completed new standards for human space flight systems. The new document is NASA-STD3001, NASA Space Flight Human System Standards (SFHSS). It consists of two-volumes:

Volume 1- Crew Health

This volume covers standards needed to support astronaut health (medical care, nutrition, sleep, exercise, etc.).

Volume 2 - Habitability and Environmental Health

This volume covers the standards for system design that will maintain astronaut performance (environmental factors, design of facilities, layout of workstations, and lighting requirements, for example). It includes classic human factors requirements; the chapters closely parallel those in NASA-STD-3000.

NASA-STD-3001, is written in general terms to be applicable to a broad range of present and future NASA programs. NASA-STD-3001 provides overarching principles applicable to all human space flight programs. Each individual human space flight program will develop program-specific, verifiable requirements that 
meet NASA-STD-3001, using a companion document, the Human Integration Design Handbook (HIDH).

For example, Volume 2 states that all programs shall define the user population and their size ranges, and that the design of systems shall then accommodate the full size range of those users. The anthropometric data to be used to define the potential crew size ranges will be in the HIDH. Together then, NASA STD-3001 and the HIDH provide a set of HFE principles that programs must follow as well as the information needed to derive verifiable requirements from these principles.

\section{HUMAN INTEGRATION DESIGN HANDBOOK (HIDH)}

The HIDH will include design goals, considerations, and authoritative data that will assist programs in developing verifiable design requirements and designs that implement these requirements. The handbook will provide the information needed to ensure compliance with Volume 2 of the standard.

Similar to NASA-STD-3001, the HIDH will be divided into topic areas which address the range of human operations in space:

- Anthropometry and Biomechanics

- Human Performance Capabilities

- Natural and Induced Environments

- Architecture and Facilities

- User Interfaces

- Hardware and Equipment

- Facility Management

- Extra Vehicular Activities (EVA)

Each of the above chapters will be subdivided into sections:

- Introduction

- Design Considerations

- Critical Design Elements

- Example Solutions and Lessons Learned

- References and Background Research

- Research Needs

Two primary uses for the handbook will be to:

- Provide data and guidance for contractual program-specific human interface requirements - Users will include program managers and system requirement writers.

- Provide data and guidance for human vehicle and system designs - Users will include human factors practitioners, engineers and designers, crews and mission / flight controllers, and training and operations developers.

\section{ON-GOING WORK}

The standards in NASA-STD-3001 are general enough that they should not need extensive work to maintain them. These guiding principles should stand the test of time. The more detailed information contained in the HIDH handbook format will only require a shortened review cycle for non-critical information. This will permit more frequent update and expansion. The handbook is intended to be a living document that can be updated as the data becomes available. The HIDH will be on-line and is intended to be an up-to-date resource of information on humans in space.

NASA-STD-3001 is nearly complete and part of the NASA technical standards system. Work is progressing on the HIDH and the first issue of the will be published at the end of 2008. At that point, NASA-STD-3000 will cease to be an applicable document, and this cadre of documents (SFHSS, Volumes 1 and 2, and the HIDH handbook) will be its replacement. Initially, the handbook will contain much of the information from NASA-STD-3000. After the first publication, work will continue to update, replace, and expand the handbook contents.

Concurrent with work on the new standards and handbook, NASA is working with the military services (primarily the Air Force) on standards and procedures needed for the Department of Defense Human Systems Integration (HSI) program. It is hoped that the extensive experience of the military can help NASA successfully use the new standards and handbook.

\section{ACKNOWLEDGEMENT}

In fond memory of Tico Foley - He brought integrity to the document during the development of NASA-STD-3001 and courage, humor and joy into our lives. 